\title{
Automatic Recognition of Medicinal Plants using Machine Learning Techniques
}

\author{
Adams Begue, Venitha Kowlessur \\ Department of Computer Science and Engineering, \\ Faculty of Engineering, \\ University of Mauritius
}

\author{
Upasana Singh \\ School of Management, Information \\ Technology and Governance, \\ University of KwaZulu-Natal (UKZN), \\ Durban, South Africa
}

\author{
Fawzi Mahomoodally \\ Department of Health Sciences, \\ Faculty of Science, \\ University of Mauritius
}

\author{
Sameerchand Pudaruth* \\ Department of Ocean Engineering \& ICT, \\ Faculty of Ocean Studies, \\ University of Mauritius
}

\begin{abstract}
The proper identification of plant species has major benefits for a wide range of stakeholders ranging from forestry services, botanists, taxonomists, physicians, pharmaceutical laboratories, organisations fighting for endangered species, government and the public at large. Consequently, this has fueled an interest in developing automated systems for the recognition of different plant species. A fully automated method for the recognition of medicinal plants using computer vision and machine learning techniques has been presented. Leaves from 24 different medicinal plant species were collected and photographed using a smartphone in a laboratory setting. A large number of features were extracted from each leaf such as its length, width, perimeter, area, number of vertices, colour, perimeter and area of hull. Several derived features were then computed from these attributes. The best results were obtained from a random forest classifier using a 10-fold crossvalidation technique. With an accuracy of $90.1 \%$, the random forest classifier performed better than other machine learning approaches such as the k-nearest neighbour, naïve Bayes, support vector machines and neural networks. These results are very encouraging and future work will be geared towards using a larger dataset and high-performance computing facilities to investigate the performance of deep learning neural networks to identify medicinal plants used in primary health care. To the best of our knowledge, this work is the first of its kind to have created a unique image dataset for medicinal plants that are available on the island of Mauritius. It is anticipated that a web-based or mobile computer system for the automatic recognition of medicinal plants will help the local population to improve their knowledge on medicinal plants, help taxonomists to develop more efficient species identification techniques and will also contribute significantly in the protection of endangered species.
\end{abstract}

Keywords - leaf recognition; medicinal plants; random forest; Mauritius

\section{INTRODUCTION}

The world bears thousands of plant species, many of which have medicinal values, others are close to extinction, and still others that are harmful to man. Not only are plants an essential resource for human beings, but they form the base of all food chains. To use and protect plant species, it is crucial to study and classify plants correctly. Identifying unknown plants relies much on the inherent knowledge of an expert botanist. The most successful method to identify plants correctly and easily is a manual-based method based on morphological characteristics. Thus many of the processes involved in classifying these plant species is 'dependent on knowledge accumulation and skills of human beings' [1]. However, this process of manual recognition is often laborious and timeconsuming. Hence many researchers have conducted studies to support the automatic classification of plants based on their physical characteristics [2][3]. Systems developed so far use varying number of steps to automate the process of automatic classification, though the processes are quite similar. Essentially, these steps involve preparing the leaves collected, undertaking some pre-processing to identify their specific attributes, classification of the leaves, populating the database, training for recognition and finally evaluating the results. Although, leaves are most commonly used for plant identification, the stem, flowers, petals, seeds and even the whole plant can be used in an automated process. An automated plant identification system can be used by nonbotanical experts to quickly identify plant species quite effortlessly.

\section{RELATED WORKS}

Several studies have been conducted in order to develop tools for the identification of plants during the last 10 years. One of the most authoritative works in the field of plant classification has been done by Wu et al. [2]. From five basic geometric features, twelve morphological features are derived and then Principle Component Analysis (PCA)) is used for dimension reduction so that fewer inputs could be sent to a probabilistic neural network (PNN). They achieved an average accuracy of $90.3 \%$ with the Flavia dataset, which is their own creation. Using a different dataset but the same classifier, Hossain and Amin (2010) achieved a similar level of accuracy with similar features [4]. Using similar features but a different dataset with only 20 species, Du et al. (2007) attained 93\% with the k-nearest neighbour classifier [5]. Using a new distance measure called 'isomap', Du et al. (2009) reached an 
accuracy of $92.3 \%$ on a dataset of 2000 images containing 20 different types of leaves [6].

Herdiyeni and Wahyuni (2012) used a fusion of fuzzy local binary pattern and fuzzy colour histogram and a probabilistic neural network (PNN) classifier on a dataset of 2448 leaf images $(270 * 240$ pixels $)$ obtained from medicinal plants from the Indonesian forests to achieve a classification accuracy of 74.5\% [7]. Prasvita and Herdiyeni (2013) developed a corresponding mobile application based on the previous research [8]. Using the kernel descriptor (KDES) as a new feature extraction technique, Le et al. (2014) developed a fully automated plant identification system [9]. The proposed technique was tested on a dataset of 55 medicinal plants from Vietnam and a very high accuracy of $98.3 \%$ was obtained with a support vector machines (SVM) classifier. Furthermore, their algorithm achieved an accuracy of $98.5 \%$ on the Flavia dataset, which is the best result published so far on this dataset [9].

Using the discrete wavelet transform to extract translation invariant features from a collection of 8 different ornamental plants in Indonesia, Arai et al. (2013) achieved an accuracy of 95.8\% using a support vector machines (SVM) classifier [10]. The size of each image was $256 * 256$ pixels. Du et al. (2013) proposed an approach based on fractal dimension features based on leaf shape and vein patterns for the recognition and classification plant leaves [11]. Using a k-nearest neighbour classifier with 20 features, they were able to achieve a high recognition rate of $87.1 \%$. Using a volumetric fractal dimension approach to generate a texture signature for a leaf and the Linear Discriminant Analysis (LDA) algorithm, Backes et al. (2009) was able to beat traditional approaches which were based on Gabor filters and Fourier analysis [12].

TABLE. I. SUMMARY OF RELATED WORKS

\begin{tabular}{|c|c|c|c|c|c|c|c|}
\hline Reference & Features & Classifier & Accuracy (\%) & Dataset & Training & Testing & Species \\
\hline Wu et al. (2007) & Shape, Veins & PNN & 90.3 & 1800 & 1480 & 320 & 32 \\
\hline Du et al. (2007) & Shape & $\begin{array}{l}\mathrm{kNN}, \\
\mathrm{MMCH}\end{array}$ & $\begin{array}{l}93 \\
90\end{array}$ & 400 & 200 & 200 & 20 \\
\hline Du et al. (2009) & Shape & $\mathrm{kNN}$ & 92.3 & $2000+$ & 1000 & $1000+$ & 20 \\
\hline Backes et al. (2009) & Texture & LDA & 89.6 & 2000 & 1200 & 800 & 10 \\
\hline Hossain and Amin (2010) & Shape & PNN & 91.4 & 1200 & \multicolumn{2}{|c|}{ Ten-fold cross-validation } & 30 \\
\hline Du et al. (2013) & $\begin{array}{l}\text { Curvature, } \\
\text { Veins }\end{array}$ & $\mathrm{kNN}$ & 87.1 & 2422 & 1695 & 727 & 30 \\
\hline Amin and Khan (2013) & Curvature & $\mathrm{kNN}$ & 71.5 & 1600 & 1120 & 480 & 100 \\
\hline Herdiyeni and Wahyuni (2012) & $\begin{array}{l}\text { Texture, } \\
\text { Colour }\end{array}$ & PNN & 74.5 & 2448 & 1938 & 510 & 51 \\
\hline Arai et al. (2013) & Wavelets & SVM & 95.8 & 120 & 96 & 24 & 8 \\
\hline $\begin{array}{l}\text { Hernandez-Serna and Jimenez- } \\
\text { Segura (2014) }\end{array}$ & $\begin{array}{l}\text { Shape, } \\
\text { Texture }\end{array}$ & ANN & 92.9 & 1800 & 1620 & 180 & 32 \\
\hline \multirow{2}{*}{ Le et al. (2014) } & Kernel & \multirow{2}{*}{ SVM } & 98.5 & 1905 & 1585 & 320 & 32 \\
\hline & Descriptor & & 98.3 & 1312 & 649 & 663 & 55 \\
\hline Munisami et al. (2015) & $\begin{array}{l}\text { Shape, } \\
\text { Colour }\end{array}$ & $\mathrm{kNN}$ & 87.3 & 640 & \multicolumn{2}{|c|}{$\begin{array}{l}\text { Leave-one-out cross- } \\
\text { validation }\end{array}$} & 32 \\
\hline Chaki et al. (2015) & $\begin{array}{l}\text { Shape, } \\
\text { Texture }\end{array}$ & NFC & 97.6 & 930 & 310 & 620 & 31 \\
\hline Siravenha and Carvalho (2015) & Shape & ANN & 97.5 & 1865 & \multicolumn{2}{|c|}{$\begin{array}{l}\text { Ten-fold } \\
\text { cross-validation }\end{array}$} & 32 \\
\hline $\begin{array}{l}\text { Carranza-Rojas and Mata- } \\
\text { Montero (2016) }\end{array}$ & $\begin{array}{l}\text { Curvature, } \\
\text { Texture }\end{array}$ & $\mathrm{kNN}$ & 87.2 & 2345 & \multicolumn{2}{|c|}{$\begin{array}{l}\text { Leave-one-out cross- } \\
\text { validation }\end{array}$} & 66 \\
\hline
\end{tabular}

Using a k-nearest neighbour $(\mathrm{kNN})$ classifier, Munisami et al. (2015) achieved an accuracy of $87.3 \%$ on a dataset of 640 leaves taken from 32 different plant species [13]. They used shape and colour information only. The images were acquired using a smartphone camera with a resolution of $1980 * 1024$.

Hernandez-Serna and Jimenez-Segura (2014) reached an accuracy level of $92.9 \%$ using the Flavia dataset [14]. Sixteen inputs (6 geometrical, 8 texture and 2 morphological features) were fed to an artificial neural network (ANN) with 60 nodes in the hidden layer and a learning rate of 0.1 over 50000 generations. Using the same dataset, Chaki et al. (2015) achieved an overall accuracy of $97.6 \%$ using a Neuro-Fuzzy classifier (NFC) with a 44-element texture vector and a 3element shape vector [15]. Using shape features only on the
Flavia dataset and Pattern Net (a flavour of neural network), Siravenha and Carvalho [16] reached a similar accuracy as Chaki et al. [15]. Their feed-forward neural network had two hidden layers with 26 neurons in each and it was trained over 100 epochs.

An interesting work was done by Carranza-Rojas and Mata-Montero (2016) in which they created two datasets: a clean one and a noisy one [17]. They implemented the Histogram of Curvature over Scale ( $\mathrm{HCoS})$ algorithm to extract contour information and the local binary pattern variance (LBPV) to extract texture information. In the best case, the clean dataset outperformed the noisy dataset by only $7.3 \%$. This suggest that images taken directly using a smartphone can produce satisfactory levels of accuracy 
compared with images which are manually processed in a lab and then classified. Earlier, Amin and Khan (2013) have used a distributed hierarchical graph neuron (DHGN) to capture curvature information using 64 feature vectors and the knearest neighbour classifier with Canberra distance to obtain an accuracy of $71.5 \%$ [18].

Table I summarises some of the works that have been done in the automated recognition of medicinal and non-medicinal plant species during the last decade. Babatunde et al. (2015) has done a good survey on different computer vision techniques and machine learning classifiers that have been used in this field during the last ten years [19]. Furthermore, Mata-Montero and Carranza-Rojas (2016) has provided a good introduction to the field and also discussed the challenges and opportunities in this domain [20].

\section{METHODOLOGY}

A database of medicinal plants which are available on the tropical island of Mauritius was created. Using a Samsung Galaxy J1 Mini smartphone, thirty (30) images of different leaves were taken for twenty-four (24) different plant species. The petiole of each leaf was removed and then placed one by one on a sheet of white paper before being photographed. The size of each image was $1024 \times 600$ pixels. The images are stored in the jpeg format.

No manual pre-processing was done on the images in order to enhance them. However, a number of post-processing operations were performed automatically on each image. From the basic attributes (width, length, area, perimeter, area of white space, area of bounding box, area of hull, perimeter of hull), 40 different attributes were derived for each leaf. These values are stored in a csv file. A Java programming environment with the open source Weka machine learning workbench was then used to assess the performance of the system [21].

\section{A. Automatic pre-processing steps}

One drawback of taking pictures using a camera, instead of using a scanner, is the presence of shadows on the image. If the shadow is not removed, this will affect all measurement. Thus, to remove the shadow, the image must first be converted to the HSV format and then split into its different colour channels. Only the second channel (saturation) is kept. This has the effect of removing the shadow from the image. To reduce noise in the image, a median blur filter with a window size of 25 is applied to the resulting image.

The next step is to perform a thresholding operation which will convert the image into a binary image with only two values: black and white pixels. This is achieved using the Otsu thresholding method. An opening operation is then performed on the images. This is an erosion operation followed by a dilation. Erosion has the effect of reducing the size of foreground (white) pixels while dilation enlarges them. This operation is important in order to clear the image from many small noisy pixels, which are the artefacts of the thresholding operation.

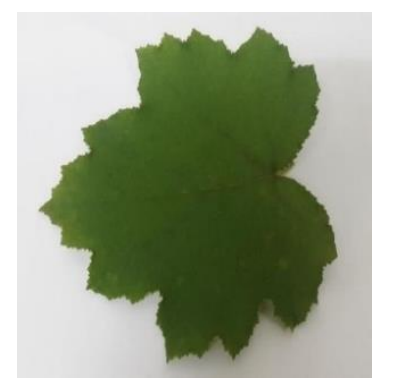

Fig. 1. Original Giant Bramble Leaf

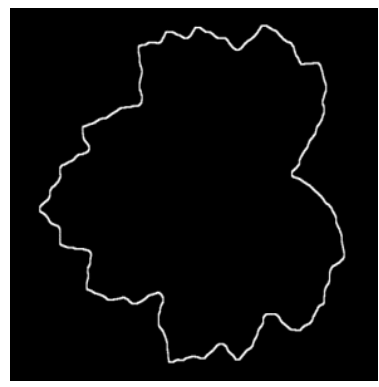

Fig. 2. Binary Image of Leaf

\section{B. Feature extraction}

A number of base features were extracted from the images in Figures 1 and 2. These are: length, width, area of the bounding box, area of leaf, perimeter of leaf, hull area, hull perimeter, number of vertices, horizontal \& vertical distance maps, $45^{\circ}$ radial map and the original RGB values of each pixel.

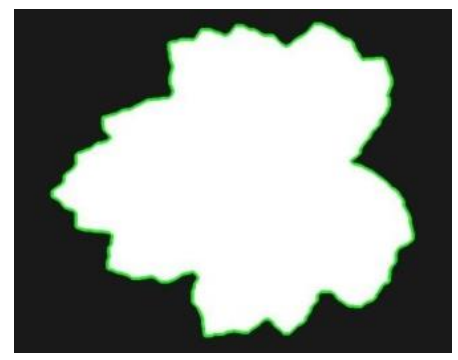

Fig. 3. Bounding Box \& Contour

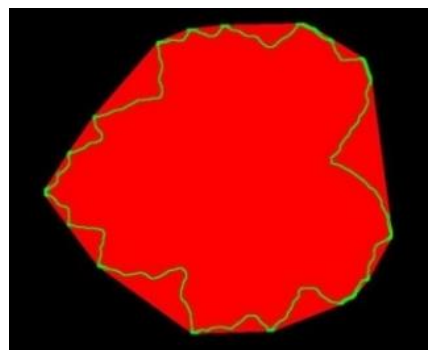

Fig. 4. Area \& Perimeter of Hull

Figure 3 shows the bounding box (in red) and the contour line (in green) around a giant bramble leaf. Using the bounding box, the length and the width of the leaf can easily be 
computed. The perimeter of the leaf is obtained from the contour line. The area of the leaf corresponds to the white space inside the green contour line. Figure 4 shows the convex hull which can be used to compute the hull perimeter and the hull area. The hull is the smallest polygon that can contain the leaf. The convex hull is also used to calculate the number of vertices in the leaf. Although the algorithm which is used to calculate the number of vertices is not very accurate, it was still a good differentiator. This is mainly because it is a raw attribute which is independent of the size of the leaf.

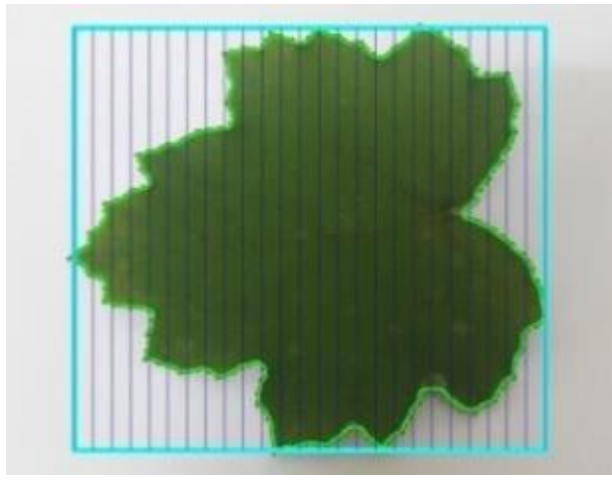

Fig. 5. Vertical Distance Map

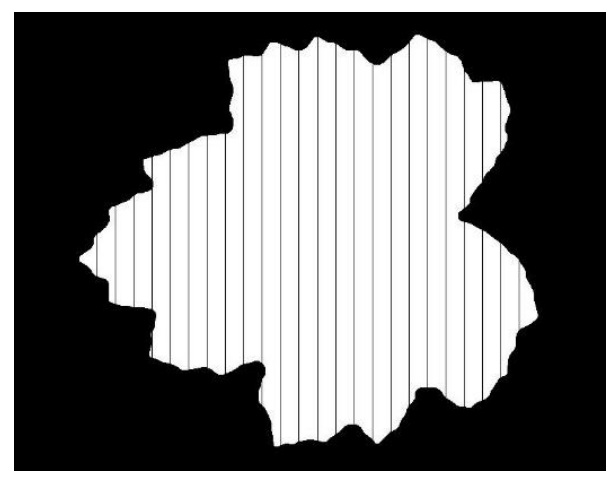

Fig. 6. Vertical Distance Map

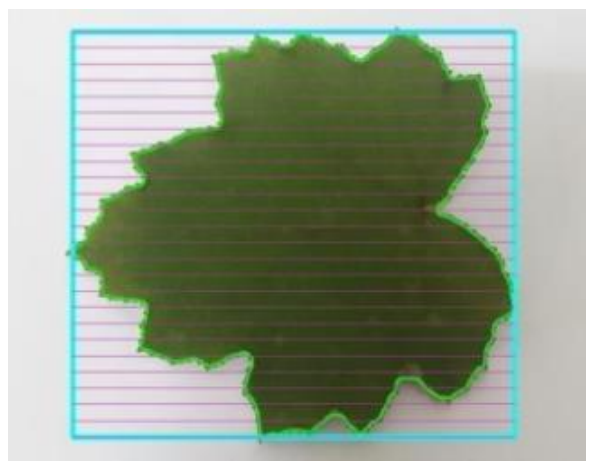

Fig. 7. Horizontal Distance Map

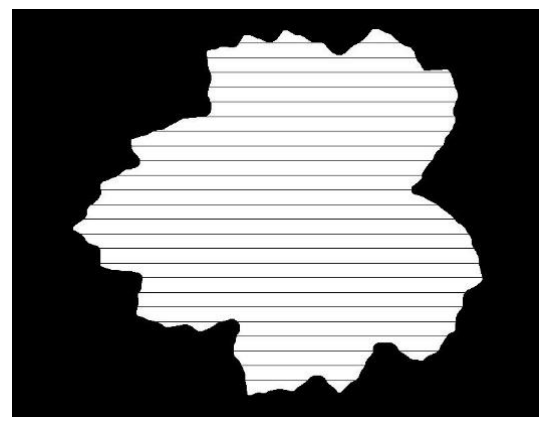

Fig. 8. Horizontal Distance Map

Figure 5 shows the vertical distance maps in which the image is divided into 24 equal strips. The aim is to find where each vertical line intercepts the contour line of the leaf. The distances between the intercepts are then computed. This is shown in Figure 6. Figure 7 shows the horizontal distance maps in which the image is divided into 24 equal strips. Again, the objective of this procedure is to locate where each horizontal line touches the boundary of the leaf, as displayed in Figure 8 . To avoid overfitting, only 12 alternate values are used for both directions. Similarly, the radial distances are computed as shown below in Figure 9 and Figure 10.

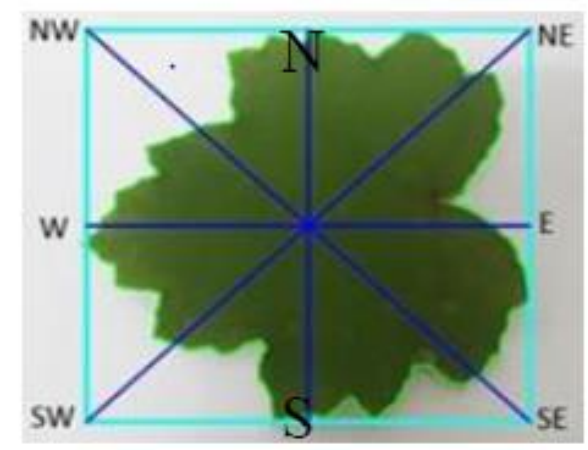

Fig. 9. Radial Map

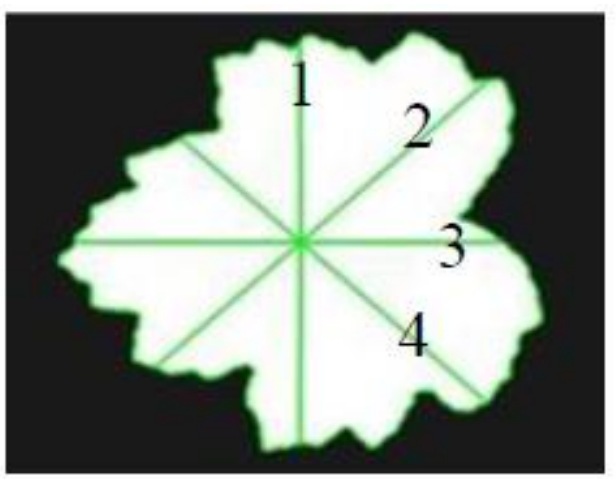

Fig. 10. Radial Map 


\section{Derived features}

Using the base features which are extracted directly from the image, a number of derived features are calculated [22]. Ratios are more suitable for comparison as they are independent of the actual size of the image in pixels. The ratios are shown below in Table II. The different plant species studied are summarized in Table V.

TABLE. II. DERIVEd FEATURES

\begin{tabular}{|l|l|l|}
\hline$\#$ & Derived Feature & Method \\
\hline 1 & aspect ratio & width/length \\
\hline 2 & circularity/roundness & area/(perimeter*perimeter) \\
\hline 3 & solidity & area/hull area \\
\hline 4 & convexity & hull perimeter/perimeter \\
\hline 5 & rectangularity & width*length/area \\
\hline 6 & hydraulic radius & area/perimeter \\
\hline 7 & lobidity & perimeter/(width+length) \\
\hline 8 & white area ratio & (area of bounding box-area)/area of \\
\hline 9 & hull ratio & hull area/hull perimeter \\
\hline 10 & red to green ratio & red/green \\
\hline 11 & red to blue ratio & red/blue \\
\hline 12 & blue to green ratio & blue/green \\
\hline 13 & N_S ratio & 1/N_S (refer to Figure 9 \& 10) \\
\hline 14 & NE_SW ratio & 2/NE_SW (refer to Figure 9 \& 10) \\
\hline 15 & E_W ratio & 3/E_W (refer to Figure 9 \& 10) \\
\hline 16 & SE_NW ratio & 4/SE_NW (refer to Figure 9 \& 10) \\
\hline 17 & vertical distance ratios (12) & length of line in leaf/width \\
\hline 18 & horizontal distance ratios & length of line in leaf/length \\
\hline & (12) & \\
\hline
\end{tabular}

\section{RESULTS AND DISCUSSION}

Medicinal plants have received much attention since they are generally perceived as safe and accessible for human utilization. However, the proper identification of plant species has major benefits for a wide range of stakeholders ranging from consumers, forestry services, botanists, taxonomists, physicians, pharmaceutical laboratories, organization fighting for endangered species, government, and the public at large.
Five different machine learning classifiers were used to assess the recognition rate. The results are shown in Table III. The Random Forest classifier achieves the best performance with an accuracy of $90.1 \%$, i.e., out of 720 leaves, 649 leaves were classified correctly while 71 were not.

The Multilayer Perceptron produced the second best accuracy at $88.2 \%$. However, due to resource constraints, the potential of neural networks has not been fully exploited and it is still possible to achieve even higher accuracy with this classifier. The k-Nearest Neighbour $(\mathrm{kNN})$ classifier had the lowest accuracy. A 10-fold cross-validation technique was used in all the experiments. The main parameters of each classifier was varied to find the ones producing the highest accuracy.

TABLE. III. PERFORMANCE OF MACHINE LEARNING ClASSIFIERS

\begin{tabular}{|c|l|c|}
\hline$\#$ & Classifier & Accuracy (\%) \\
\hline 1 & Random Forest (numTrees=100) & 90.1 \\
\hline 2 & $\begin{array}{l}\text { Multilayer Perceptron Neural Network } \\
\text { Epochs=500) }\end{array}$ & 88.2 \\
\hline 3 & $\begin{array}{l}\text { Support Vector Machine (PolyKernel and } \\
\text { c=4.0) }\end{array}$ & 87.4 \\
\hline 4 & Naïve Bayes & 84.3 \\
\hline 5 & k-Nearest Neighbour $(\mathrm{k}=1)$ & 82.5 \\
\hline
\end{tabular}

Figure 11 shows the confusion matrix obtained when using the Random Forest classifier with 100 trees and 6 attributes in each iteration. The value 25 (first number in the second row) in the matrix indicates that 25 Antidesma leaves were correctly classified. Out of the five remaining leaves, one was incorrectly classified as an Avocado leaf, one as a Fandamane leaf, another as a Jackfruit, and last two as Guava. From the first column, it can be seen that two Bigaignon Rouge and one Pomegranate leaves were misclassified as Antidesma. The high values in the diagonal line indicate that the recognition was very successful. Another important observation is that six Coriander leaves were misclassified as Bitter Gourd and the only two Bitter Gourd leaves that were not correctly carried were predicted as Coriander leaves. These observations could be explained by the fact that both these plants have highly lobed leaves. 


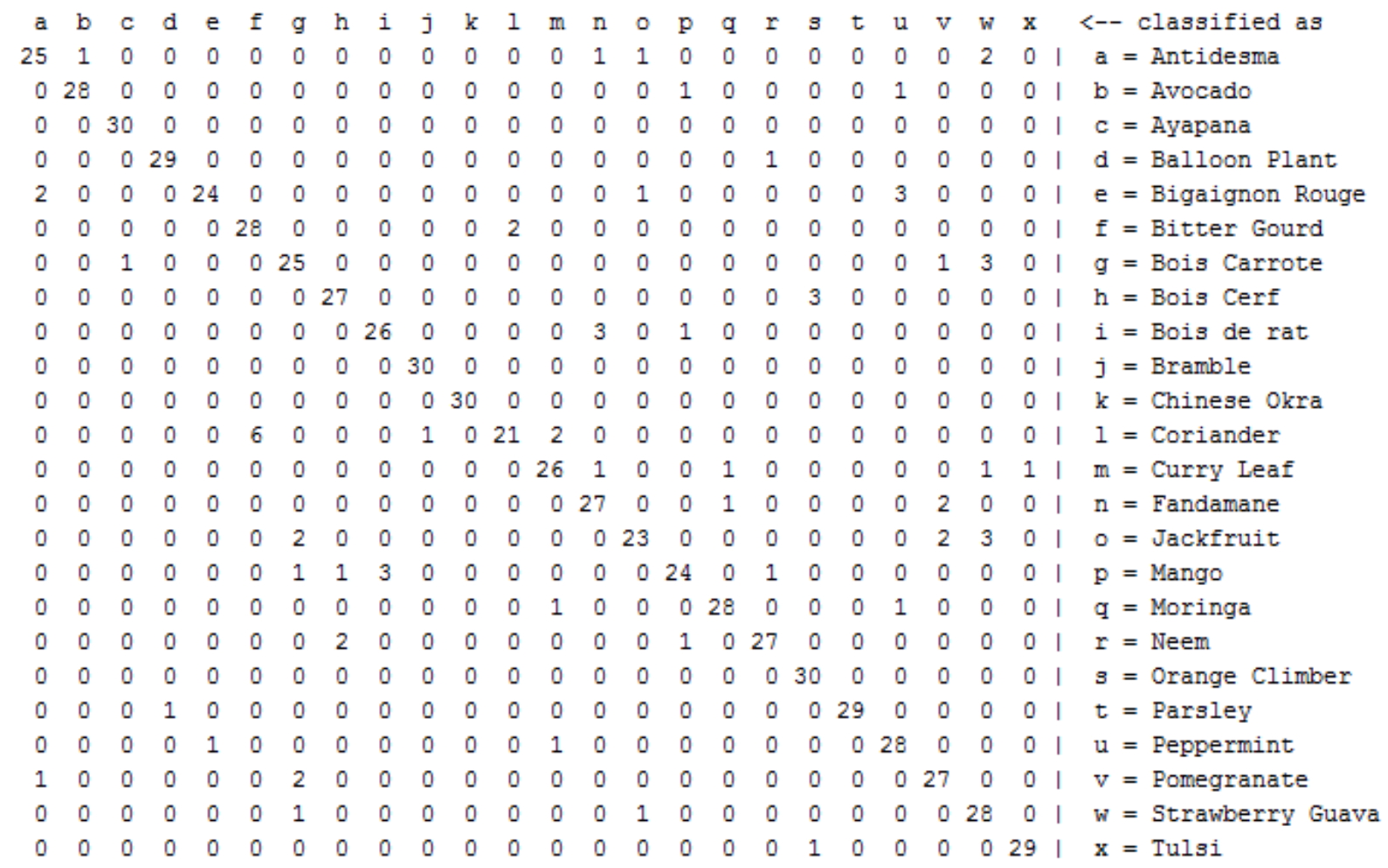

Fig. 11. Confusion Matrix for Random Forest with 100 Trees

Besides the overall accuracy, the performance of the automated system was also assessed on a class-wise basis. Recall is the proportion of leaves, for each class, that was correctly picked out from the entire set. Precision is the proportion of correctly identified leaves out of all the leaves that are predicted to be of a specific plant while F-measure can simply be considered as the average of these two values. Table IV shows that Ayapana, Bramble, Chinese Okra and Orange Climber has a perfect recall of $100 \%$ while Coriander has the lowest recall of 70\%. Only the Chinese Okra and Parsley has a precision value of $100 \%$ while the Strawberry Guava has the lowest precision at $76 \%$. Thus, Table IV provides us with much useful information which can be used to both gauge the strengths of the system and address its weaknesses as well. Plants which have low recall and low precision must be relooked into. For example, new features must be designed and extracted that bring out the uniqueness in such leaves and are determinative of their species.
TABLE. IV. Performance AsSESSMENT by SPECIES USING A RANDOM FOREST WITH 100 TREES

\begin{tabular}{|c|c|c|c|c|}
\hline$\#$ & Species & Precision & Recall & F-Measure \\
\hline 1 & Antiderma & 0.89 & 0.83 & 0.86 \\
\hline 2 & Avocado & 0.97 & 0.93 & 0.95 \\
\hline 3 & Ayapana & 0.97 & 1.00 & 0.98 \\
\hline 4 & Balloon Plant & 0.97 & 0.97 & 0.97 \\
\hline 5 & Bigaignon Rouge & 0.96 & 0.80 & 0.87 \\
\hline 6 & Bitter Gourd & 0.82 & 0.93 & 0.87 \\
\hline 7 & Bois Carotte & 0.81 & 0.83 & 0.82 \\
\hline 8 & Bois Cerf & 0.90 & 0.90 & 0.90 \\
\hline 9 & Bois de rat & 0.90 & 0.87 & 0.88 \\
\hline 10 & Bramble & 0.97 & 1.00 & 0.98 \\
\hline 11 & Chinese Okra & 1.00 & 1.00 & 1.00 \\
\hline 12 & Coriander & 0.91 & 0.70 & 0.79 \\
\hline 13 & Curry Leaf & 0.87 & 0.87 & 0.87 \\
\hline 14 & Fandamane & 0.84 & 0.90 & 0.87 \\
\hline 15 & Jackfruit & 0.89 & 0.77 & 0.82 \\
\hline 16 & Mango & 0.89 & 0.80 & 0.84 \\
\hline 17 & Moringa & 0.93 & 0.93 & 0.93 \\
\hline 18 & Neem & 0.93 & 0.90 & 0.92 \\
\hline 19 & Orange Climber & 0.88 & 1.00 & 0.94 \\
\hline 20 & Parsley & 1.00 & 0.97 & 0.98 \\
\hline 21 & Peppermint & 0.85 & 0.93 & 0.89 \\
\hline 22 & Pomegranate & 0.84 & 0.90 & 0.87 \\
\hline 23 & Strawberry Guava & 0.76 & 0.93 & 0.84 \\
\hline 24 & Tulsi & 0.97 & 0.97 & 0.97 \\
\hline \multicolumn{2}{|c|}{ Average } & 0.91 & 0.90 & 0.90 \\
\hline
\end{tabular}


Besides investigating the effect of different classifiers, the effect of the number of plant species in the dataset on the overall accuracy of the system was also studied. As expected, with only eight features, a very high accuracy of $97.9 \%$ is obtained, as shown in Figure 12. Next, the number of plant species is doubled to 16 but the accuracy decreases by only $3.1 \%$. After an additional set of eight new types of leaves are added, the accuracy drops by $4.7 \%$. Munisami et al. (2015) reported very similar results but with a different dataset containing 32 plants [13].

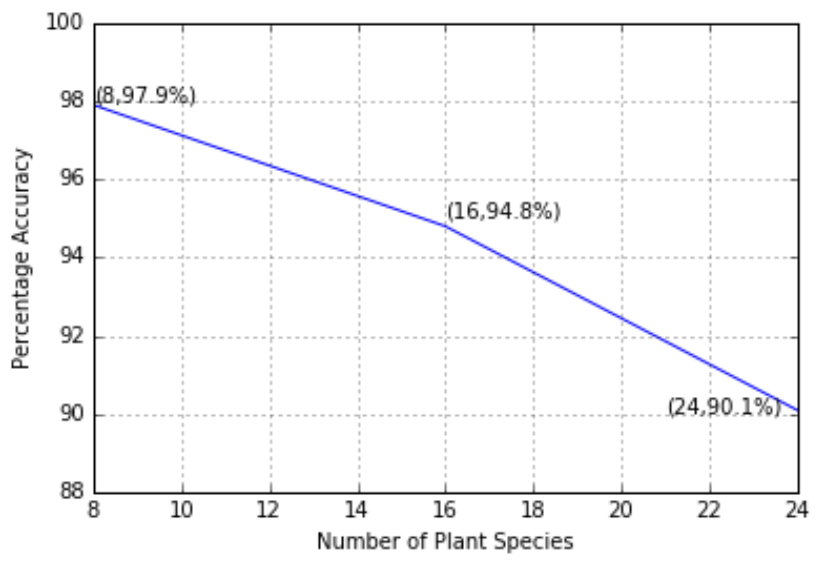

Fig. 12. Number of Plant Species v/s Percentage Accuracy

As shown in Figure 13, increasing the number of leaves per plant species has a positive impact on the classification accuracy. The peak performance is achieved when using 25 leaves per plant. There is no improvement in accuracy beyond this threshold. This is an important result which can be used by researchers and scientists to decide on the number of samples that they must collect in their studies. Munisami et al. (2015) performed a similar assessment [13]. However, they collected only 20 samples per species and therefore they could not arrive at this threshold value [13].

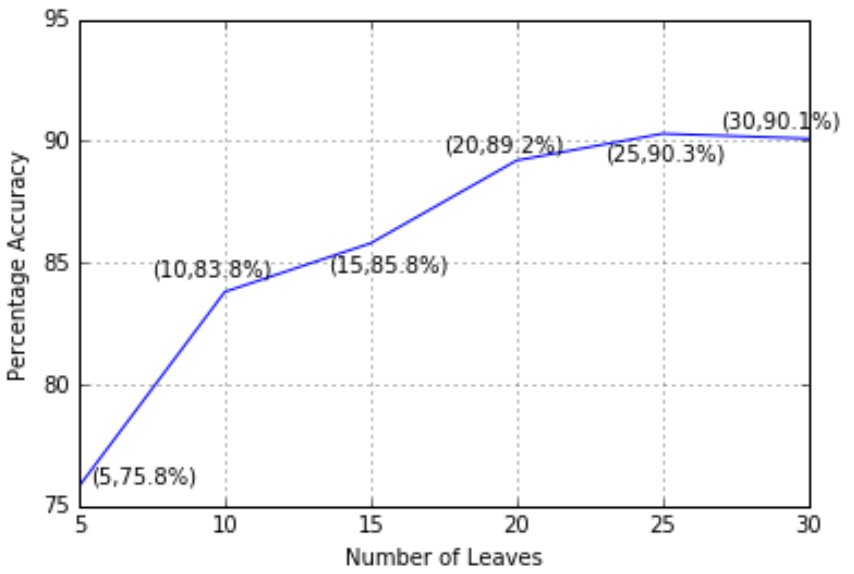

Fig. 13. No. of Leaves per Plant v/s Percentage Accuracy

Using the chi-squared $\left(\chi^{2}\right)$ statistical test in Weka, the $k$ best features from the dataset were selected. The results are shown in Figure 14. The eight $(k=8)$ best features were: white area ratio (first position), rectangularity, number of dents, hull ratio, hydraulic radius, aspect ratio, lobidity, and solidity at the eight position. An accuracy of $77.1 \%$ was obtained using these 8 features. The next best features were: convexity (ninth position), NE_SW ratio, SE_NW ratio, N_S ratio, E_W ratio, circularity, blue to green ratio and the red to green ratio (sixteenth position). Using the 16 best features lead to a significant boost in accuracy by $12.1 \%$. The accuracy was only minimally better with the 24 best features and using more than 32 features did not bring any improvement in the accuracy.

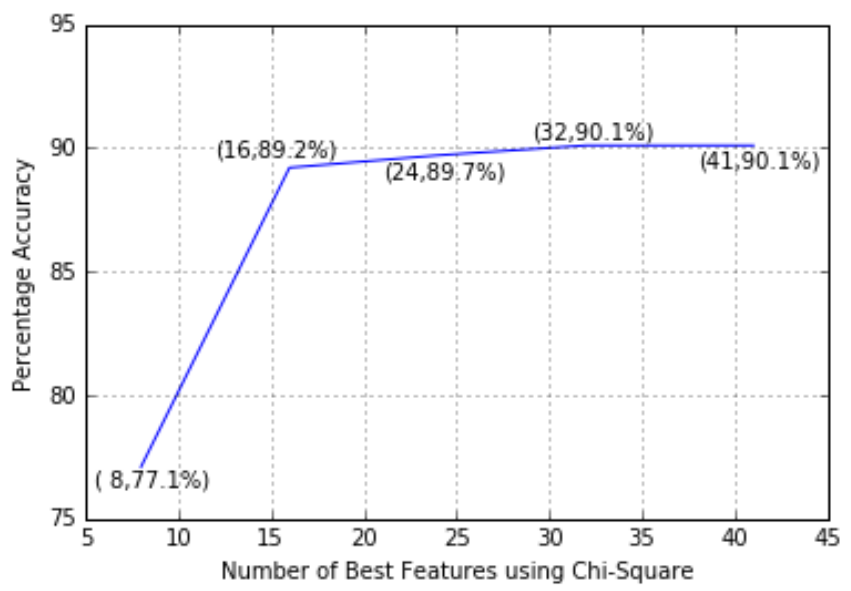

Fig. 14. Number of Best Features v/s Percentage Accuracy

Although literature on leaf-based recognition of plant species using image processing and data mining techniques are abundant, only a handful of researchers have applied these techniques on medicinal plants. Countries like China, India, Indonesia, Malaysia, and Vietnam have vast repositories of medicinal plants and therefore it is no wonder that many of the research works on medicinal plants come from these countries [23]. The novelty of this work resides in the creation of a unique image dataset for medicinal plants that are available on the island of Mauritius.

A new measure called lobidity has also been proposed. This is the seventh best differentiating feature according to the chisquared test. Although the majority of researchers have been able to achieve accuracies above 90\%, improvements are still possible. The work of Mata-Montero and Carranza-Rojas (2016) outlines the different approaches that have been used for plant classification, including morphometrics (curvature, texture and venation), DNA barcoding, and crowd sourcing [20]. More importantly, they outlined the challenges of collecting, classifying and sharing huge datasets and discuss the opportunities that crowd sourcing and deep learning offer to this community of researchers.

\section{CONCLUSION}

A new dataset on medicinal plants of Mauritius has been made publicly available on the machine learning repository portal. In this paper, computer vision techniques have been used to extract several shape-based features from the leaves of medicinal plants. Machine learning algorithms were then used to classify the leaves from 24 different plant species into their appropriate categories. The highest accuracy of $90.1 \%$ was obtained from the random forest classifier. This excellent performance indicates the viability of such computer-aided 
approaches in the classification of biological specimens and its potential applicability in combatting the 'taxonomic crisis'. A web-based or mobile computer system for the automatic recognition of medicinal plants will help the local population to improve their knowledge on medicinal plants, help taxonomists to develop more efficient species identification techniques and will also contribute significantly in the protection of endangered species. For future research, in an attempt to achieve even higher accuracies, probabilistic neural networks and deep learning neural networks would be investigated.

\section{REFERENCES}

[1] Gao, W. and Lin, W., 2012. Frontal Parietal Control Network Regulates the Anti-Correlated Default and Dorsal Attention Networks. Human Brain Mapping, 33(1), 192-202.

[2] Wu, S.G., Bao, F.S., Xu, E.Y., Wang, Y.X., Chang, Y.F. and Xiang, Q.L., 2007. A Leaf Recognition Algorithm for Plant Classification using Probabilistic Neural Network. 7th IEEE International Symposium on Signal Processing and Information Technology, Giza, Egypt, 11-16.

[3] Zhang X., Liu Y., Lin H., Liu Y. (2016) Research on SVM Plant Leaf Identification Method Based on CSA. In: Che W. et al. (eds) Social Computing. ICYCSEE 2016. Communications in Computer and Information Science, Vol 624, Springer, Singapore.

[4] Hossain, J. and Amin, M.A., 2010. Leaf Shape Identification Based Plant Biometrics. 13th International Conference on Computer and Information Technology, Dhaka, Bangladesh, 458-463.

[5] Du, J.X., Wang, X.F. and Zhang, G.J., 2007. Leaf shape based plant species recognition. Applied Mathematics and Computation, 185, 883893.

[6] Du, M., Zhang, S. and Wang, H., 2009. Supervised Isomap for Plant Leaf Image Classification. 5th International Conference on Emerging Intelligent Computing Technology and Applications, Ulsan, South Korea, 627-634.

[7] Herdiyeni, Y. and Wahyuni, N.K.S., 2012. Mobile Application for Indonesian Medicinal Plants Identification using Fuzzy Local Binary Pattern and Fuzzy Color Histogram. International Conference on Advanced Computer Science and Information Systems (ICACSIS), West Java, Indonesia, 301-306.

[8] Prasvita, D.S. and Herdiyeni, Y., 2013. MedLeaf: Mobile Application for Medicinal Plant Identification Based on Leaf Image. International Journal of Advanced Science, Engineering and Information Technology, $3,5-8$.

[9] Le, T.L., Tran, D.T. and Hoang, V.N., 2014. Fully Automatic leaf-based plant identification, application for Vietnamese medicinal plant search. Fifth Symposium on Information and Communication Technology, Hanoi, Vietnam, 146-154.

[10] Arai, K., Abdullah, I.N. and Okumura, H., 2013. Identification of Ornamental Plant Functioned as Medicinal Plant Based on Redundant Discrete Wavelet Transformation. International Journalof Advanced Research in Artificial Intelligence, 2(3), 60-64.

[11] Du, J.X., Zhai, C.M. and Wang, Q.P., 2013. Recognition of plant leaf image based on fractal dimension features. Neurocomputing, 116, 150156.

[12] Backes, A.R., Casanova, D. and Bruno, O.M., 2009. Plant Leaf Identification based on Volumetric Fractal Dimension. International Journal of Pattern Recognition and Artificial Intelligence, 23(6), 1451160 .

[13] Munisami, T., Ramsurn, M., Kishnah, S. and Pudaruth, S., 2015. Plant leaf recognition using shape features and colour histogram with $\mathrm{k}$ nearest neighbour classifiers. Procedia Computer Science, 58, 740-747.

[14] Hernandez-Serna, A. and Jimenez-Segura, L.F., 2014. Automatic Identification of species with neural networks. PeerJ 2:e563; doi:10.7717/peerj.563.

[15] Chaki, J., Parekh, R. and Bhattacharya, S, 2015. Plant leaf recognition using texture and shape features with neural classifiers. Pattern Recognition Letters, 58, 61-68.
[16] Siravenha, A.C.Q. and Carvalho, S.R., 2015. Exploring the use of Leaf Shape Frequencies for Plant Classification. 28th SIBGRAPI Conference on Graphics, Patterns and Images, Salvador, Brazil, 297-304.

[17] Carranza-Rojas, J. and Mata-Montero, E., 2016. Combining Leaf Shape and Texture for Costa Rican Plant Species Identification. CLEI Electronic Journal, 19(1), Paper 7.

[18] Amin, A.H.M. and Khan, A.I., 2013. One-Shot Classification of 2-D Leaf Shapes using Distributed Hierarchical Graph Neuron (DHGN) Scheme with k-NN Classifier. Procedia Computer Science, 24, 84-96.

[19] Babatunde, A., Armstrong, L., Diepeveen, D. and Leng, J., 2015. A survey of computer-based vision systems for automatic identification of plant species. Journal of Agricultural Informatics, 6(1), 61-71.

[20] Mata-Montero, E. and Carranza-Rojas, J., 2016. Automated Plant Species Identification: Challenges and Opportunities. IFIP Advances in Information and Communication Technology, 481, 26-36.

[21] Hall, M., Frank, E., Holmes, G., Pfahringer, B., Reutemann, P. and Witten, I. H., 2009. The WEKA Data Mining Software: An Update. SIGKDD Explorations, 11(1).

[22] Russ, J.C., 2011. The Image Processing Handbook. CRCPress, USA.

[23] FAO, 2016. Food and Agriculture Organisation of the United Nations (online). Available from: http://www.fao.org/docrep/005/AA010E/AA010e02.htm [Accessed 30th December 2016].

TABLE. V. Plant SPECIES

\begin{tabular}{|l|l|}
\hline & \\
Image & \\
\hline Scientific name & Antidesma madagascariense \\
\hline English name & Antidesma \\
\hline Mauritian name & Bigaignon batard \\
\hline Medicinal uses & $\begin{array}{l}\text { Effective against dysentery and skin } \\
\text { infections }\end{array}$ \\
\hline & \\
\hline & \\
\hline Image & \\
\hline Scientific name & Persea americana \\
\hline English name & Avocado \\
\hline Mauritian name & Avocat \\
\hline Medicinal uses & $\begin{array}{l}\text { Reduce the risk of eye cataract; Control } \\
\text { cholesterol level }\end{array}$ \\
\hline & \\
\hline Image & \\
\hline Scientific name & Bardiospermum halicacabum \\
\hline Mauritian name & Ayapana \\
\hline Medicinal uses & Stomachic; anti-ulcerous; Fights cough \\
\hline & \\
\hline & \\
\hline & \\
\hline & \\
\hline & \\
\hline & \\
\hline & \\
\hline & \\
\hline & \\
\hline & \\
\hline
\end{tabular}




\begin{tabular}{|c|c|}
\hline Mauritian name & Pocpoc \\
\hline Medicinal uses & $\begin{array}{l}\text { Management of Type II diabetes mellitus; } \\
\text { Healing skin infections }\end{array}$ \\
\hline \multicolumn{2}{|l|}{ Image } \\
\hline Scientific name & Psiloxylon mauritianum \\
\hline English name & Bigaignon wood/Red bigaignon \\
\hline Mauritian name & Bois bigaignon/Bigaignon rouge \\
\hline Medicinal uses & $\begin{array}{l}\text { Treatment and management of amenorrhea, } \\
\text { dysentery and Type II diabetes mellitus }\end{array}$ \\
\hline \multicolumn{2}{|l|}{ Image } \\
\hline Scientific name & Momordica charantia \\
\hline English name & Bitter gourd \\
\hline Mauritian name & Margose \\
\hline Medicinal uses & Management of Type II diabetes mellitus \\
\hline \multicolumn{2}{|l|}{ Image } \\
\hline Scientific name & Pittosporum senacia \\
\hline English name & Not available \\
\hline Mauritian name & Bois carotte \\
\hline Medicinal use & Treatment of stomach disorders \\
\hline \multicolumn{2}{|l|}{ Image } \\
\hline Scientific name & Olea lancea \\
\hline English name & Not available \\
\hline Mauritian name & Bois cerf \\
\hline Medicinal uses & Effective against cough and hypertension \\
\hline \multicolumn{2}{|l|}{ Image } \\
\hline Scientific name & Coptosperma borbonicum \\
\hline English name & Not available \\
\hline Mauritian name & Bois de rat \\
\hline Medicinal uses & Treatment of fever \\
\hline \multicolumn{2}{|l|}{ Image } \\
\hline Scientific name & Rubus alceifolius \\
\hline English name & Giant bramble/Wild raspberry \\
\hline Mauritian name & Framboisier/Piquant loulou \\
\hline
\end{tabular}

\begin{tabular}{|c|c|}
\hline Medicinal uses & Management of Type II diabetes mellitus \\
\hline \multicolumn{2}{|l|}{ Image } \\
\hline Scientific name & Luffa acutangula \\
\hline English name & Chinese okra/Silky gourd \\
\hline Mauritian name & Pipengaille \\
\hline Medicinal uses & $\begin{array}{l}\text { Prevention of cardiovascular disease; } \\
\text { Effective against hypertension }\end{array}$ \\
\hline \multicolumn{2}{|l|}{ Image } \\
\hline Scientific name & Coriandrum sativum \\
\hline English name & Coriander \\
\hline Mauritian name & Cotomili/Coriandre \\
\hline Medicinal uses & Management of Type II diabetes mellitus \\
\hline \multicolumn{2}{|l|}{ Image } \\
\hline Scientific name & Murraya koenigii \\
\hline English name & Curry tree \\
\hline Mauritian name & Cari poulet \\
\hline Medicinal uses & Management of hypertension \\
\hline \multicolumn{2}{|l|}{ Image } \\
\hline Scientific name & Aphloia theiformis \\
\hline English name & Fandamane \\
\hline Mauritian name & Fandamane \\
\hline Medicinal uses & $\begin{array}{l}\text { Management of Type II diabetes mellitus } \\
\text { Prevention of eye cataract }\end{array}$ \\
\hline \multicolumn{2}{|l|}{ Image } \\
\hline Scientific name & Artocarpus heteophyllus \\
\hline English name & Jackfruit \\
\hline Mauritian name & Jack \\
\hline Medicinal uses & Management of Type II diabetes mellitus \\
\hline \multicolumn{2}{|l|}{ Image } \\
\hline Scientific name & Magnifera indica \\
\hline English name & Mango \\
\hline Mauritian name & Mangue \\
\hline Medicinal uses & Management of Type II diabetes mellitus \\
\hline
\end{tabular}




\begin{tabular}{|c|c|}
\hline Image & \\
\hline Scientific name & Moringa oleifera \\
\hline English name & Moringa \\
\hline Mauritian name & Brede mouroum \\
\hline Medicinal uses & $\begin{array}{l}\text { Management of Type II diabetes mellitus; } \\
\text { Control cholesterol level }\end{array}$ \\
\hline \multicolumn{2}{|l|}{ Image } \\
\hline Scientific name & Azadirachta indica \\
\hline English name & Neem \\
\hline Mauritian name & Neem \\
\hline Medicinal uses & Management of Type II diabetes mellitus \\
\hline \multicolumn{2}{|l|}{ Image } \\
\hline Scientific name & Toddalia asiatica \\
\hline English name & Orange climber \\
\hline Mauritian name & Patte poule \\
\hline Medicinal uses & Treatment of asthma \\
\hline \multicolumn{2}{|l|}{ Image } \\
\hline Scientific name & Petroselinum crispum \\
\hline English name & Parsley \\
\hline Mauritian name & Persil \\
\hline Medicinal uses & $\begin{array}{l}\text { Management of Type II diabetes mellitus; } \\
\text { Control cholesterol level; Treatment of } \\
\text { kidney diseases }\end{array}$ \\
\hline
\end{tabular}

\begin{tabular}{|c|c|}
\hline Image & \\
\hline Scientific name & Mentha x piperita \\
\hline English name & Peppermint \\
\hline Mauritian name & Menthe \\
\hline Medicinal uses & Effective against indigestion \\
\hline \multicolumn{2}{|l|}{ Image } \\
\hline Scientific name & Punica granatum \\
\hline English name & Pomegranate \\
\hline Mauritian name & Grenade \\
\hline Medicinal uses & $\begin{array}{l}\text { Prevention of cardiovascular disease; Control } \\
\text { cholesterol level; Effective against diarrhea }\end{array}$ \\
\hline \multicolumn{2}{|l|}{ Image } \\
\hline Scientific name & Psidium cattleyanum \\
\hline English name & Guava \\
\hline Mauritian name & Goyave de chine \\
\hline Medicinal uses & $\begin{array}{l}\text { Management of Type II diabetes mellitus; } \\
\text { Control cholesterol level }\end{array}$ \\
\hline \multicolumn{2}{|l|}{ Image } \\
\hline Scientific name & Ocimum tenuiflorum \\
\hline English name & Holy basil/Tulsi \\
\hline Mauritian name & Tulsi \\
\hline Medicinal uses & $\begin{array}{l}\text { Management of Type II diabetes mellitus; } \\
\text { Control cholesterol level }\end{array}$ \\
\hline
\end{tabular}

